\title{
'When it faded in her ... it faded in me': a qualitative study exploring the impact of care-giving on the experience of spousal intimacy for older male care-givers
}

\author{
Anne Fee ${ }^{1 \star}$ (D), Sonja McIlfatrick ${ }^{1}$ and Assumpta Ryan ${ }^{1}$ \\ ${ }^{1}$ School of Nursing and Institute of Nursing and Health Research, Ulster University, Newtownabbey, UK \\ ${ }^{\star}$ Corresponding author. Email: fee-a1@ulster.ac.uk
}

(Accepted 7 June 2019; first published online 13 August 2019)

\begin{abstract}
Older male care-givers play an increasingly important role in informal care-giving, yet they have received little attention in the literature. The aim of this study was to explore the impact of care-giving on the experience of spousal intimacy for older male care-givers. Twenty-four older male care-givers, drawn from a region of the United Kingdom, participated in one-to-one interviews about their care-giving role. Thematic analysis was used to analyse data, and the study was underpinned by theories of masculinity. Three main themes were identified: (a) 'Impact of care-giving on the experience of sexual intimacy'; (b) 'Impact of care-giving on the experience of emotional intimacy'; and (c) 'Not up for discussion'. When sexual intimacy declined, some older male care-givers prioritised emotional intimacy; some struggled with the decline; and some were reluctant to discuss the issue. Additionally, some care-givers reported that they had not received support from external support providers for declining sexual or emotional intimacy. Intimacy has been highlighted as important for care-givers given its link with care-giver wellbeing and quality of life. Results of this study suggest that sexual and emotional intimacy was an issue for older male care-givers, and that this issue should be considered by external support providers as part of a holistic assessment of need in order to tailor effective support.
\end{abstract}

Keywords: care-givers; male; intimacy; masculinity; gender; support

\section{Introduction}

The importance of sexual and emotional intimacy on the quality of marital/longterm relationships is becoming increasingly recognised (Heiman et al. 2011; Davies et al., 2012). Studies with heterosexual older couples have demonstrated that ongoing intimacy can improve quality of life, and physical and mental wellbeing (Droes et al., 2006; Hayes and Boylstein, 2009; Davies et al., 2012). It has 
also been found that for spousal care-givers (male and female), satisfaction with intimacy significantly contributes to care-giver wellbeing (Nogueira et al., 2015; Brotman et al., 2016). According to Svetlik et al. (2005), declining intimacy can result in negative perceptions about the quality of the relationship and consequently higher care-giver burden. Thus, identifying factors which may contribute to decline in intimacy could potentially increase our knowledge about the experience of caregivers and inform future care-giver support.

Within the literature it has been noted that the onset of chronic illness can result in various losses which can impact aspects of the relationship. This includes reduction in shared activities (O'Shaughnessy et al., 2010), companionship, communication and sexual intimacy (Davies et al., 2010; Harris et al., 2011). Consequently, the care-giving partner may experience a decline in the perceived relationship quality, through decreased mutuality, support, marital intimacy and satisfaction (Baikie, 2002).

\section{Sexual and emotional intimacy}

Sexual Intimacy has been defined as 'the behaviour directly associated with sexual relations and being sexually aroused' (Sinnott and Shifren, 2001). In a recent integrative review of literature, Holdsworth and McCabe (2018) explored the impact of dementia on relationships, intimacy and sexuality in later life, from the perspective of the care-giver, the person with dementia and the couple. In the review, the authors examined 13 international papers over a 20 -year period. Findings not only suggested a lack of research in this area, but also highlighted various methodological issues such as stage and type of illness, age of participant and small sample size. Notably, the authors concluded that for most couples, sexual activity had stopped or declined. For some couples, this had been replaced with other forms of physical expression such as holding hands and hugging. Some spousal caregivers reported that they did not recognise their partner as their spouse anymore, or they were no longer in love with them (Davies et al., 2010). Similarly, in their qualitative study comparing dementia care-giver dyads $(\mathrm{N}=74)$ with an older dyads control group $(\mathrm{N}=21)$, Nogueira et al. (2016) reported decreased sexual satisfaction. They found that the care-giving role impacted on spousal intimacy as it involved caring for a spouse with a progressive chronic condition (dementia), which involved various behavioural symptoms and memory impairment. This resulted in feelings of loss and emotional burden, and consequently a lack of sexual intimacy. These findings are consistent with other literature which demonstrated that not only does sexual intimacy often decline in care-giving dyads, but it was often replaced with greater emotional intimacy (Davies et al., 2010; Harris et al., 2011; Boylstein and Hayes, 2012; Galinsky and Waite, 2014; Merrick et al., 2016).

According to Sternberg (1997), emotional intimacy is defined as 'the emotional component of a relationship, including feelings of closeness, warmth, connectedness, and bondedness in loving relationships'. Harris et al. (2011) undertook a phenomenological study $(\mathrm{N}=10)$ examining how dementia impacted on couple intimacy from a care-giver perspective. Findings revealed that prior to diagnoses, the quality of the marital relationship was important for the impact of the condition on the relationship; and, for all couples, declining emotional intimacy was due to ambiguity of intimacy, or overwhelming stress of the care-giving role. 


\section{Older male care-givers}

The present study sought to contribute to knowledge and to existing literature by exploring spousal intimacy from the perspective of older male care-givers. Whilst previous studies have explored the impact of chronic conditions such as dementia on spousal intimacy/sexuality (Davies et al., 2010, 2012; Harris et al., 2011; Merrick et al., 2016; Youell and Callaghan, 2016; Roelofs et al., 2017), none of them has taken account of the older male care-givers' perspective.

Traditionally the domain of females, the number of informal male family caregivers is rising (Pöysti et al., 2012). It is estimated that approximately 42 per cent of informal care-givers in the United Kingdom (UK) are male, with this number rising to 59 per cent for care-givers aged over 85 years (Carers UK, 2015). There is a growing interest in their particular approach to care-giving (Hong and Coogle, 2014), however, there is a dearth of literature about this population.

Previous studies that have examined gender as a factor in spousal care-giving have tended to focus on the female care-giver perspective (O'Shaughnessy et al., 2010; Youell and Callaghan, 2016), or on comparisons between care-giving husbands and wives (Boylstein and Hayes, 2012; Davies et al., 2012; Nogueira et al., 2016). It has previously been argued that for male care-givers the loss of spousal sexual intimacy is linked with a decline in masculinity (Clarke et al., 2003). Hayes and Boylstein (2009) examined this in their qualitative study of spousal caregivers in the United States of America (13 males and 15 females). Study authors argued that women perceived their caring role as more 'motherly' than spousal, whereas men expressed a greater desire for sexual intimacy, and appeared to continue to identify with 'husband' in spite of their care-giving role. This raises questions about the link between sexual intimacy and self-identity. In their systematic review of the impact of dementia on marriage, Evans and Lee noted that male spousal care-givers appeared to be reluctant to continue with sexual relations if they were unsure about consent, thus identifying strongly with the role of 'guardian' (Evans and Lee, 2014). Similarly, this protective approach to care-giving was noted in a study by Milligan and Morbey (2016). Given that previous studies suggest that not only are there gender differences in the experiences of marital intimacy in later life (Simonelli et al., 2008; Hayes and Boylstein, 2009; Davies et al., 2012; Evans and Lee, 2014), but for older male spousal care-givers, it can be reasonably assumed that sexual intimacy and identification with traditional masculine traits may be connected, as indicated in analysis of the data from the present study.

Older male care-givers are reported to be at risk of social isolation and lack of support (Milligan and Morbey, 2016). Arguably, older male care-givers are also at risk of isolation and lack of support regarding their experience of spousal intimacy, particularly in light of myths and ageist stereotypes which portray older adults as asexual. Dominguez and Barbagallo (2016) reported that societal prejudices and misconceptions about sexuality in older age can inhibit individuals from discussing their sexual needs with health-care staff, for fear of raising something inappropriate (Griffiths, 1988). According to Dominguez and Barbagallo (2016), there is a lack of support for sexuality in older age, and a failure to incorporate sexuality as a need in holistic assessment, or indeed to provide specialised gender-specific training about sexuality to health and social care professionals (Davies et al., 2012). 


\section{Theoretical framework}

It has been theorised that Connell's (1995) hegemonic masculinity theory provides an understanding of how masculine ideology can influence men's approach to caregiving (Milligan and Morbey, 2016). Connell provided the basis for O'Neil's gender role conflict theory (O'Neil, 1981), which suggests that men's wellbeing is limited by adherence to masculine ideology such as 'fear of femininity', or fear of displaying traits which could be seen as feminine. Figure 1 is an illustration of how Connell's (1995) theory has shaped O'Neil's gender role conflict theory, which underpins this study and a number of previous similar studies. This was considered to be a suitable framework, given previous reports that men view care-giving as a 'feminised activity', which is at odds with traditional masculine traits (Baker et al., 2010). The framework aids interpretation of the current data by providing a theoretical underpinning of Connell's hegemonic masculinity theory, and through this, illuminates how care-giving may contribute to a diminishment of traditional masculine identity.

In summary, it is known that older male care-givers tend to be isolated, have a poor awareness of external support services, and that care-giving impacts on the physical, mental and financial areas of male care-giver's lives (Milligan and Morbey, 2016). However, there is a dearth of literature about how the care-giving role impacts on the area of intimacy for older male care-givers. This is an important area given the significance of intimacy for quality of life and care-giver wellbeing (Davies et al., 2012; Nogueira et al., 2015), and also the reported acceleration to residential placement for the care recipient when intimacy declines (Davies et al., 2010).

The current study contributes to the literature in two ways. First, it provides valuable insight into the experience of spousal intimacy for older male care-givers, by analysing qualitative data generated through interviews with older male caregivers (all heterosexual, in long-term committed relationships). Second, it considers the influence of masculinity in the approach of male care-givers to spousal intimacy, and the implications of this for the future development of support for male care-givers.

\section{Methodology}

The aim of this study was to gain an understanding of the impact of care-giving on the experience of spousal intimacy for older male care-givers. The design employed was qualitative, using semi-structured interviews and thematic analysis (Braun and Clarke, 2006). Considering the sensitive nature of the topic, a qualitative approach using one-to-one interviews was considered the most suitable for the collection of data.

\section{Sample}

A purposive sample of interview participants (Silverman, 2004) was chosen for the study. Participants were recruited from organisations within statutory and community/voluntary sectors in a region of the UK. The inclusion criteria were: male caregiver; over 60 years old; primary care-giver for a chronically ill spouse/partner; living in the community; and ability to give informed consent. Chronic illnesses of the 


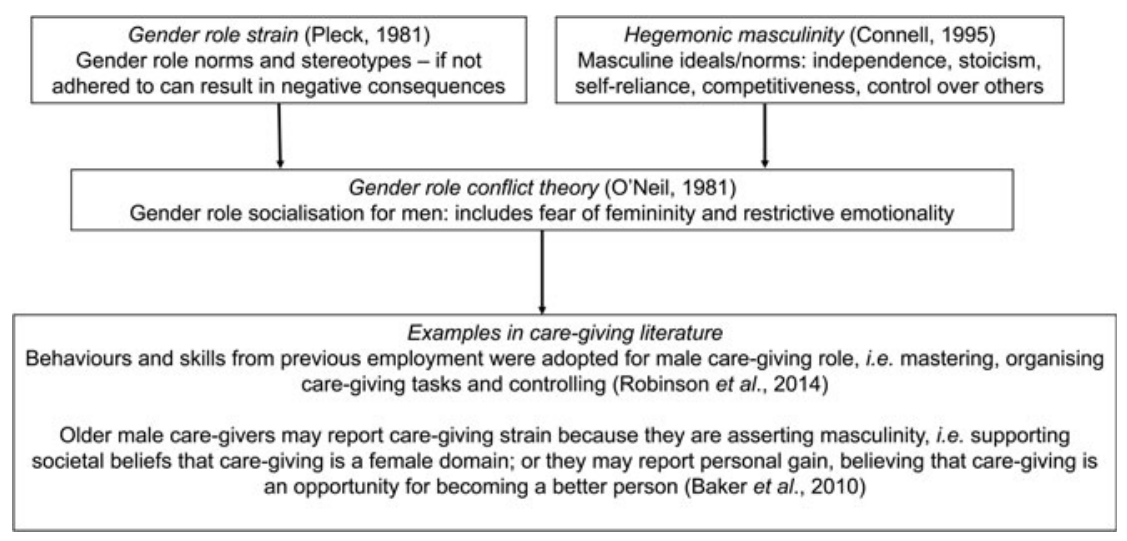

Figure 1. Theoretical framework.

care recipients were dementia $(\mathrm{N}=16)$, stroke $(\mathrm{N}=4)$, Parkinson's disease $(\mathrm{N}=2)$, multiple sclerosis $(\mathrm{N}=1)$ and severe epilepsy $(\mathrm{N}=1)$. Details of participants' characteristics are in Table 1.

\section{Ethical considerations}

Due to the sensitive nature of the subject area, a number of ethical considerations were noted. Primarily, it was recognised that interviews could raise potentially distressing or embarrassing issues. This was addressed by the implementation of a 'distress protocol' which detailed suggestions such as taking a break from the interview or ensuring the participant had sufficient information about support organisations if needed. Also, in light of the fact that the researcher was female, and all participants were male, it was acknowledged that time spent building rapport was important, and that when sensitive or personal issues (such as sexual intimacy) were discussed, maintaining rapport was crucial. Rapport was established by the researcher arriving on time, making general conversation upon arrival, on occasions self-disclosure ('I grew up around here', I also have a labrador') and looking at family photographs. Maintaining this rapport involved employing empathy and listening skills throughout the interview, maintaining a friendly and open disposition, and acknowledging feelings where appropriate. The researcher was satisfied that for most participants, rapport was present by body language, facial expressions, a feeling of flow and connection, and by the responses given and the way they were given.

The study was granted ethical approval from OREC (UK), Ulster University Filter Committee, and Northern Health and Social Care Trust (REC reference 17/WM/0019).

\section{Data collection}

Twenty-four semi-structured interviews were undertaken with older male care-givers (on their own) at home or in a local venue. The interview schedule 
Table 1. Participant characteristics

\begin{tabular}{|c|c|c|c|c|}
\hline Identifier & $\begin{array}{l}\text { Length of time } \\
\text { caring (years) }\end{array}$ & $\begin{array}{l}\text { Age of } \\
\text { care-giver }\end{array}$ & $\begin{array}{c}\text { Length of relationship } \\
\text { (years) }\end{array}$ & $\begin{array}{l}\text { Age of } \\
\text { partner }\end{array}$ \\
\hline Clive & 9 & 72 & 46 & 69 \\
\hline Simon & 13 & 75 & 52 & 75 \\
\hline Sean & 2 & 82 & 59 & 81 \\
\hline Dessie & 8 & 73 & 49 & 75 \\
\hline Jack & 4 & 68 & 39 & 66 \\
\hline Joseph & 9 & 68 & 32 & 59 \\
\hline Robert & 4 & 69 & 41 & 70 \\
\hline Gerry & 14 & 61 & 27 & 54 \\
\hline Mark & 7 & 65 & 40 & 61 \\
\hline Mike & 4 & 76 & 51 & 76 \\
\hline Ian & 22 & 70 & 42 & 65 \\
\hline Gary & 6 & 66 & 33 & 66 \\
\hline Harry & 8 & 81 & 60 & 78 \\
\hline Dan & 6 & 66 & 38 & 68 \\
\hline Paul & 3 & 81 & 54 & 78 \\
\hline Tim & 4 & 79 & 56 & 77 \\
\hline Noel & 2 & 72 & 16 & 60 \\
\hline Patrick & 15 & 73 & 37 & 70 \\
\hline Bobby & 5 & 68 & 41 & 63 \\
\hline Aidan & 6 & 70 & 48 & 69 \\
\hline Andy & 5 & 72 & 39 & 69 \\
\hline Berty & 2 & 68 & 44 & 64 \\
\hline Colin & 7 & 66 & 47 & 68 \\
\hline Alan & 4 & 83 & 58 & 83 \\
\hline
\end{tabular}

was developed in liaison with the inter-disciplinary project steering group (comprising statutory and voluntary-sector personnel, a male care-giver and academics). The schedule was informed by study objectives and relevant theory, and aimed to elicit information about experience of care-giving, including information about the impact of care-giving on spousal intimacy. The schedule covered aspects such as how the care-giving role had affected sexual intimacy or emotional intimacy within the relationship, and experiences of formal and informal support. The intention was to use the term 'intimacy' in its broadest sense during interviews. In this way, if participants felt comfortable enough to discuss sexual intimacy, then they could. However, if they did not appear to be comfortable, then they would not feel obliged to refer to sexual intimacy. In general, if participants talked openly 
about other intimate aspects of care, then the researcher would have gently encouraged discussion about sexual intimacy, at the appropriate time. However, introducing sexual intimacy was a risk which had to be carefully managed.

The semi-structured nature of the interviews ensured that whilst there was a focus, questions were open enough to allow for exploration of issues. The interview schedule was piloted with two older male care-givers which resulted in two modifications to the original schedule. The first modification was to collect demographic information during or at the end of the interview as opposed to the beginning, and the second was to change the order of two questions and add further prompts in order to improve the flow of questions. A $£ 20$ supermarket voucher was given to all interview participants, and funding was made available to arrange alternative care for the duration of the interview, if needed. Interviews were conducted by the first author (AF), a middle-aged female, with previous experience of working with male care-givers in a Health Trust in the UK, and who had recently undertaken specialised in-depth interview training. Interviews lasted between 45 and 90 minutes and were digitally recorded (with written consent).

\section{Data analysis}

Cross-sectional thematic analysis was used to analyse data (Braun and Clarke, 2006). Thematic analysis is a flexible approach to analysing qualitative data, which can be used in its own right or as a process which is performed within a different analytic tradition (Braun and Clarke, 2006). This approach involved six key phases: (a) familiarisation with the data, (b) generating initial codes, (c) searching for themes, (d) reviewing themes, (e) defining and naming themes, and (f) producing the report.

Interviews were transcribed verbatim, and the first author (AF) checked all transcripts against audio recordings to ensure accuracy. After reading and re-reading transcripts for familiarisation, an initial coding framework was developed as a result of line-by-line coding and importing data into NVivo 11 qualitative data management software by the first author (AF). The coding framework was underpinned by the research aim, relevant theory and key literature, with codes/sub-themes being developed based on relevance to these, as opposed to frequency of words or concepts. Two authors agreed on the final coding framework (AF and AR). Codes and themes were regularly discussed within the research team and project steering group. These discussions involved the use of mind maps (Buzan and Buzan, 1994) to illustrate relationships between codes and themes, thus allowing three overarching themes to be developed and refined (see Table 2).

\section{Rigour}

The trustworthiness of the present study was established by ensuring credibility, transferability, and dependability and confirmability (Lincoln and Guba, 1985).

\section{Credibility}

Initial emerging themes were peer reviewed and any differences of opinion were discussed until consensus was reached. Key themes were then developed, refined 
Table 2. Description of overarching themes, sub-themes and codes

Theme 1: The impact of care-giving on the experience of sexual intimacy

Sub-theme:

- Decline or loss of sexual intimacy

Codes:

Impact of illness on physical contact Reasons for loss of sexual contact
Sub-theme:

- Impact of the loss/decline of sexual intimacy on the relationship

Codes:

Dealing with loss of sexual contact - positive

Dealing with loss of sexual contact - negative

Resignation

Theme 2: The impact of care-giving on the experience of emotional intimacy

Sub-theme:

- Prioritising emotional intimacy

Codes:

Impact of increased emotional intimacy

Gratitude
Sub-theme:

- Loss of emotional intimacy

Codes:

Decreasing conversation

Impact of loss of closeness

Theme 3: Not up for discussion

Sub-theme:

- A taboo subject?

Codes:

Impact of illness on marriage

A taboo subject?
Sub-theme:

- Getting on with it

Codes:

Coping strategy

Household tasks take priority

and named. Codes were checked against data to enhance credibility (Quinn-Patton, 2002). The multi-disciplinary project steering group was involved throughout, with the development of the interview schedule, and also the coding process by way of reviewing and discussing evolving themes in order to assist with interpretation of the data.

\section{Transferability}

Transferability was assured though the provision of descriptive data including field notes, detail on sample size, interview schedule, inclusion criteria, and interview procedure.

\section{Dependability and confirmability}

Dependability and confirmability were assured through an audit trail comprising: researcher reflexive journal, team meeting notes, steering group minutes and defined analytical techniques for thematic analysis (coding mind maps). 


\section{Findings}

Analysis of data from a larger study which explored support needs for older male care-givers revealed that sexuality and intimacy was an important element in men's experience of providing care. As a sub-study of this larger study, the current study explored the impact of care-giving on the experience of spousal intimacy with older male care-givers. Analysis revealed two main aspects of the impact of care-giving on intimacy: impact on sexual intimacy and impact on emotional intimacy. Data from participants who did not discuss the issue were also categorised, which resulted in the third overarching theme: 'Not up for discussion'. Pseudonyms were used for direct quotes.

\section{Theme 1: The impact of care-giving on the experience of sexual intimacy}

\section{Sub-theme 1: Decline of sexual intimacy - 'Even if I could have I wouldn't have'}

Decline of sexual intimacy was reported by all participants. One reason given for declining sexual intimacy appeared to be inhibited desire. Some participants described symptoms which related to their partner's illness such as urinating and defecating, and they were unable to relate to their partner in a sexual way:

I suppose the intimate thing would be it changes your relationship ... When you have to evacuate somebody's bowel because they are so constipated for so long, that changes how you relate to them, and in that sense a relationship probably becomes more distant as a way of coping. (Gary)

You're lying there beside them, trying to hold them in a seizure and you know rightly at the same time they're urinating themselves and possibly defecating, right, you don't think of it any more as a sexual thing. That goes out the window, you know what I mean? (Gerry)

Other reasons given for decline in sexual intimacy could not be as easily associated with the care-giving role as those outlined above, however, they do seem to be unique to older care-givers. For instance, a number of men had attributed decline in sexual intimacy to older age or to a previous health condition associated with older age, such as prostate or bladder cancer. These quotes illustrate the impact that a previous treatment for cancer had on sexual activity:

I took prostate cancer. That was about 12 years ago ... That meant that sex or intercourse didn't happen because when you have 40 shots of radio ... The cancer, thankfully, is gone, but it does have that effect ... I'm 75 years old. After 60, you start to wane off anyway. (Simon)

Awk no, sure we are old now ... No, that sort of thing has gone away from us. Then with my bladder cancer, that didn't do anything like that any good. (Sean)

A further obstacle to sexual activity reported by the participants was communication difficulties in the advanced stages of illness. Lack of communication seems to have created a degree of ambiguity to sexual intimacy. One participant explained 
that although sexual activity would have satisfied him, due to lack of communication from his wife he was unsure about whether it would have satisfied her and so 'it wouldn't have been fair', for the past ten years they 'have been close, just kissing and cuddling'. Thus, it appeared that the type and stage of illness of the care recipient may have influenced participants' experience of intimacy. Another participant described his wife's reaction when he kissed her goodnight:

If [wife] is tucked in bed and I'm going to bed I always give her a kiss goodnight, on her forehead, and if I try to kiss her on the lips she will bite me, because anything coming around there is food. (Dessie)

\section{Sub-theme 2: Impact of declining sexual intimacy on the relationship - 'You lose the} sexual contact in your life... That is difficult to deal with'

Perceptions of the impact of declining sexual intimacy on the relationship differed between participants. Although some men attributed this decline to their own age or health, others viewed it as a natural progression of their partner's illness and rationalised it as such. Also, some men focused on increased emotional intimacy, which they saw as important in maintaining closeness and connection:

We both realise we're getting on in life ... You know we actually talk more now ... we've more time for each other. (Gerry)

We always cuddle, it's the last thing we do before going to sleep is have a kiss and cuddle. We can have a cuddle any time of the day. (Jack)

Some participants portrayed resignation or a sense of acceptance. For Gerry, a 'fear of God' provided a coping mechanism and would suggest that his strong religious belief also influenced his perspectives on intimacy:

It's not something that bothers me personally, that we don't have a regular sex life ... I'm not going to go outside of my house looking for it, you know and I think that maybe comes a wee bit from my knowledge of God and the fear of God. (Gerry)

On the other hand, some men experienced declining sexual intimacy as a struggle. Even though participants were at different stages of the care-giving trajectory, they had all been in long-term committed relationships, and reported that before their partner's illness they were satisfied with their relationship and committed to their partner:

Intimacy has disappeared. Just physically can't respond. We always made a point of a kiss and a big cuddle at least once a day but intimacy has disappeared, it's non-existent. (Robert)

For a small number of men, their marriage vows or religious beliefs seemed to conflict with ideas they were considering for dealing with the decline of sexual intimacy: 
You lose the sexual contact in your life. There's no way you're messing about with it, but I miss it ... That is difficult to deal with. It puts up the evil challenge of ... I stood at the front of my church, and I made some promises, and when that hits you, it starts to challenge you as much as, well, do I, or don't I, [wife] doesn't know me, she's like a baby, and you get into that quagmire of thinking, and some people would admire me for sticking to my guns ... I'm a frustrated old bugger. (Dessie)

A participant described how other people had said to him, 'if you still have those urges sort them out', however, he said that there was 'no temptation'. He went on, however, to describe how he had considered other options. This was the first time he had discussed this deeply personal area with anyone (the researcher), and when asked if he had thought about discussing it with anyone else he said he 'wouldn't know where to go':

I'd love to see what the professionals said that I should do. Should I adopt the moral issues, i.e. my wedding vows, or is there, in their eyes, because of the condition that my wife is in, is there somebody saying, it's okay. But, that's a curiosity I've got, but there's no temptation. (Dessie)

\section{Theme 2: The impact of care-giving on the experience of emotional intimacy \\ Sub-theme 1: Prioritising emotional intimacy - 'It just probably tests the glue that holds you together'}

Participants had different experiences of the impact of care-giving on emotional intimacy. Some had prioritised emotional intimacy over sexual intimacy as a way of sustaining their partnership and gaining reward and satisfaction from their caregiving role. For example, these participants described small ways of continuing to share everyday experiences and were grateful for this:

We still get on well yet. I'll go over beside her and she'll sit and hold your hand there in the chair ... Somebody said to me, 'would it have been better if [wife] had have had a heart attack and died?' I said, 'no, it wouldn't, [wife]'s still there'. I suppose everybody looks at it differently. (Tim)

We get stronger, it gets stronger, we do everything together, everywhere we go [wife] wants your hand. (Mike)

Every Saturday, I'd take her into town and have lunch. Sometimes, you get no reaction to it, but sometimes it's 'That's nice' or 'That's lovely' ... I get satisfaction from that. (Simon)

\section{Sub-theme 2: Loss of emotional intimacy - 'We've always done everything together and now we don't do anything really'}

The following participants reported a decline in emotional intimacy and felt a profound sense of loss. Given that these are spousal care-givers who live with their partner, lack of conversation as the illness progressed led to a lack of emotional intimacy which seemed to compound their sense of loneliness: 
[Wife] doesn't talk. This is one of the first things, you know, when it really began to, sort of, bite. One of the first things that [wife] lost was the ability to talk. (Bobby)

I mean another aspect of it is my loneliness, [wife] just loves watching the TV and then falling asleep ... I might as well be alone in the house, there's no communication. (Robert)

We've no family and we've always done everything together and now we don't do anything really. (Joseph)

I felt very lonely. I think that was the real suicidal part of it, just sitting here ... it was like mourning somebody and still living with them and that's very true. (Colin)

A small number of participants who spoke about lack of intimacy were considering placement in long-term residential care, one had recently moved his wife into a residential facility and another one was considering permanent placement as, with sadness, he felt he had come to the end of his role as care-giver:

The future, well, the future I know is she's going to be in a home, I know that, it took a long time coming to her. (Clive)

\section{Theme 3: Not up for discussion}

\section{Sub-theme 1: A taboo subject? - 'I don't think I need to elaborate'}

Findings in Theme 3 suggest that some men did not wish to discuss 'intimacy', either because they did not view it as a priority in the relationship or because they did not feel comfortable discussing it.

The question 'How has your partner's illness affected your relationship/marriage?' was a preliminary question, to signal that the discussion was moving to a more personal level. Subsequent questions depended on participant's responses to previous questions that may have been of a sensitive nature (such as personal care) and the response to the question above. If there was still evidence of good rapport, the researcher then asked, 'And has your partner's illness affected your intimacy at all'? A small number of men sought clarification at this point (e.g. 'Do you mean sex-wise'?). Others seemed comfortable, and proceeded to refer to or discuss sexual intimacy (either briefly or at length). On the other hand, if the researcher felt that the rapport was not sufficient, or there was some discomfort around previous discussion regarding personal care, the researcher did not ask about intimacy, and these participants responded to the original question of 'How has your partner's illness affected your relationship/marriage?' These participants described issues which perhaps were more important to them, such as memory loss or lack of opportunity for joint activity:

I have to understand that there are a lot of things she might not remember. We still talk a wee bit, but she doesn't talk really much now. (Andy)

The only way it has affected it is we can't go out the same now. (Dan) 
Well we used to like going away on holidays and we used to run to England a lot.

Well that's all stopped now because you just can't do it. (Mark)

Additionally, a small number of men acknowledged sexual intimacy in the relationship but referred to it in an historical context, and did not wish to give further detail, for example:

Not really, I mean we're of an age where it's very platonic, we share everything and, the intimacy - we still would be shy, I mean whenever we were getting ready at night for bed [wife] used the bathroom or another bedroom, things like that but, you know, we're good. (Mike)

\section{Sub-theme 2: Getting on with it - 'You adapt, you overcome, you get on with it'}

Data included in this sub-theme indicated that some participants adopted a very practical approach to their care-giving role, and did not portray sexual or emotional intimacy as being an important element in their marriage. Their 'getting on with it' strategy appeared to indicate that their priority within their care-giving role was to manage practical tasks, and they seemed focused and organised:

The clothes are sitting out and I have to wash them and hang them up. I try to get them all dried. I have to be one step ahead all the time. I have to make a list of all the shopping. I'm afraid of being at home and caught cold. As I say, I do all the cooking. All the cooking. It's all mine. (Andy)

I just deal with it in the present. We just get on ... I devised, you know, got the care package going with Bluebird, direct payments, all of this, and I had to arrange my own. I think I got so involved in the caring part of it that I really didn't think about anything else, you know. It was just, basically, it was something that had to be done, and make sure that it operated properly. (Bobby)

To tell you the truth, cleaning is basically my hobby now, washing, cleaning, cooking ... I've removed a lot of stuff, ornaments and stuff, I've decluttered because what it means is less things to dust, less things to lift really. (Dan)

You have it to do so you just get on and do it. Nobody else is going to do it for you. (Mark)

\section{Discussion}

In this study, semi-structured qualitative interviews were conducted with 24 older male spousal care-givers, with the aim of exploring the impact of care-giving on their experience of intimacy. Study findings revealed that all participants experienced a decline of sexual intimacy with their long-term partner/spouse. However, these changes were not always found to be associated with their partner's illness. For a small number of participants this was due to their own age/health status, or to the importance given to intimacy by them. Some participants appeared to accept that change in intimacy was a result of ageing or illness progression, and 
many of these participants reported expressions of emotional intimacy. Others, however, felt frustrated or increasingly lonely as their spousal intimacy decreased, and a number of participants did not discuss the issue.

The impact of care-giving on the experiences of intimacy for care-givers has been largely unexplored in care-giving literature, and even less so for older male care-givers in committed heterosexual relationships. Previous evidence has indicated that within care-giving spousal relationships, sexual intimacy often declines because the care-giver becomes the 'parent', and they cease to see themselves as spouse (Nogueira et al., 2013), thus rendering the role of care-giver and spouse as incompatible (Kaplan, 2001), or that lost sexual intimacy is the result of the burden of care (Simonelli et al., 2008; Nogueira et al., 2016).

Even though there is little understanding about the impact of care-giving on older male care-givers, international literature about sexuality in later life is steadily increasing. Recent studies have found that men in later life continue to place importance on sexual activity and tend to remain sexually active (Fileborn et al., 2017). However, they may see it as context-dependent (Fileborn et al., 2017), where 'intimacy' is central to their sexual experience (Sandberg et al., 2013). Similarly, Palacios-Ceña et al. (2012) suggested that marriage or having a long-term partner provides the context for most sexual activity among heterosexual couples in later life. Also, Waite et al. (2017) note that ill-health (for older men) is not necessarily detrimental to sexual activity, and where couples think that it is important, sexual activity of some kind may still continue.

In the current study, various reasons were reported for changes in sexual intimacy, and participants spoke about the impact of this on themselves and their relationships. Three participants attributed the decline in sexual intimacy to 'old age'. Given that the sample were all 'older' (i.e. over 60 years old), there is an increased likelihood that health conditions associated with advancing years may have impacted on intimacy. For instance, two of the participants explained that previous treatment for prostate and bladder cancer was the reason for their decline in sexual intimacy. Further analysis of the data also revealed that of the participants who appeared to be more accepting of decline in intimacy $(\mathrm{N}=4)$, three were towards the older end of the age spectrum (75-83). The six participants who seemed to struggle with decline in intimacy tended to be towards the younger end (66-73). These findings may indicate a difference between care-givers at the older and the younger end of the age spectrum in the sample, in their approach to spousal intimacy. Although it is not possible to draw a conclusion from such a small sample, this finding is consistent with other research (see Fileborn et al., 2017). Furthermore, it also raises questions about the influence of other factors, such as age, age-related health conditions, stage in the care-giving trajectory, type of illness of the care recipient, or external factors such as religion or culture, on the experience of intimacy for older male care-givers.

Some participants described an acceptance of declining sexual intimacy. They portrayed a transition from previous sexual activity to greater emotional intimacy focusing on good experiences within the relationship, such as going out to lunch, holding hands or talking more. These participants appeared to want to maintain emotional intimacy as a source of support and reassurance, to increase 
their level of satisfaction with the relationship, and to decrease feelings of frustration and isolation.

Maintaining emotional intimacy in this way could be interpreted as what some participants perceive as a natural part of a long marriage/long-term relationship. This expectation, however, would only be possible if the quality of the pre-morbid relationship was suitable (Molyneaux et al., 2011). Participants in the current study frequently spoke about their sense of commitment and reciprocity, explaining that 'she would do it for me'. Findings such as these may be explained with Rusbult's (1983) model of investment (i.e. commitment and relationship satisfaction) within the social exchange theory, whereby individuals stay within a relationship if rewards outweigh costs. On balance, a long marriage/long-term committed relationship will involve many costs and rewards - not necessarily experienced within the same time-frame, and possibly perceived differently by spouses/partners and outsiders. This is illustrated in the data by participants who describe small rewards/satisfactions within their care-giving role, such as their partner thanking them for what they do or holding their hand. Furthermore, participants used phrases such as 'in sickness and in health', 'till death do us part', and referred to commitment and marriage vows - this could explain why participants sometimes overlooked personal sacrifice in favour of investing in the marriage/relationship, which for them is the reward. This perhaps demonstrates that although care-giving within a long-term committed relationship could be seen as a 'cost/sacrifice' to outsiders, some participants experienced it as a reward, as a way of repaying their spouse/partner, which provided balance in the relationship and validation for their role. Arguably, this sense of investment in a relationship through cost and reward could apply to both male and female spousal care-givers. However, validation and experiencing reward for their care-giving role may be especially important for male care-givers, who have been reported to view care-giving as a 'feminised' activity and at odds with traditional masculine traits (Baker et al., 2010).

Just as some participants reported an increase in emotional intimacy when sexual intimacy declined, others portrayed resignation or struggled with changes in sexual intimacy. These participants reported gradual decline in all forms of intimacy as their partners' illness progressed, and they struggled with the challenges of adjusting to a changing role. Describing feelings of grief, anger, frustration, guilt and worry, several men found that they were unable to come to terms with the deteriorating situation. Participants reported feeling stressed and isolated, and did not know how much longer they could sustain their caring role. For some in this group, long-term placement in residential care was a realistic option being considered. It has previously been recognised that declining emotional intimacy, as perceived by the care-giver, has accelerated admission to long-term residential care. For example, Davies et al. (2010) undertook a study with 14 dementia and nine mild memory impairment (MMI) care-givers, using focus groups and content analysis to investigate the impact of dementia and MMI on sexuality in spousal relationships. Study findings revealed that due to care-giving stressors, care-givers experienced uncertainty about the future of the relationship and the majority had considered placement in residential care. Authors also recognised the importance of support for intimacy from external providers, suggesting couples counselling or new relationship rituals to compensate for the emotional and cognitive 
decline of the affected partner. This, they suggest, may lessen care-giver burden and delay admission into residential care.

Although the present study examined spousal care-giving intimacy with a sample of older male care-givers, it is acknowledged that older males and females can have similar experiences of spousal care-giving. However, previous research has speculated that although males and females may have similar care-giving experiences, their approach and coping strategies may be different - based on gender (Chen, 2014; Hong and Coogle, 2014). Analysis of data in the present study has resulted in questions around whether the male care-giving approach is influenced by gender and, if it is, how this impacts on subsequent support. For example, findings in Theme 3 of the present study related to participants who did not discuss intimacy. This may indicate discomfort around discussing such a personal area, perhaps with a female researcher (Thorpe et al., 2017). Alternatively, it may indicate an approach where intimacy is viewed as low priority within the context of the caregiving role. Even though this could also apply to female care-givers, the difference is that older men are likely to have had jobs/careers, where they felt valued and visible (Russell, 2007). The transition to care-giving, traditionally the domain of females, may result in male care-givers feeling that their masculinity is challenged by providing unpaid, 'unskilled' care (Baker et al., 2010; Hrženjak, 2013). Therefore, it is possible that they may have constructed their care-giving in a way that was less challenging by 'professionalisation' of care tasks, and aligning their role to one of management and problem solving. Examples of this in the current data include participants who found solutions to household difficulties such as replacing carpets with wooden floors (to avoid hoovering), employing someone to clean or de-cluttering. Within this approach, some male care-givers may view task completion and problem solving as a high priority and intimacy as a low priority. In their UK study with 15 older male care-givers, Milligan and Morbey (2016) employed narrative analysis to examine how older male care-givers coped with care-giving and how it impacted on their sense of identity. Findings highlighted male caregivers' tendency to use their past experience (through work or education) in their approach to care-giving, therefore re-affirming their masculinity by continuing in their pre-care-giving role of provider/protector. Authors also noted that societal views of male care-givers can sometimes have a diminishing effect on masculinity, as some care-givers in the narratives explained that they were ridiculed by peers for learning how to cook or sew as it was seen to be 'unmanly'. Consequently, male care-givers in the study experienced increased isolation as a result of their care-giving role.

A sense of 'diminishing' masculinity as a result of the care-giving role is also demonstrated in the current data. Some of the participants stated that they used medication to help them cope with care-giving. Colin was prescribed antidepressants as he was experiencing suicidal feelings. When he mentioned the use of antidepressants as a coping strategy to a friend, he was ridiculed. His friend seemingly had interpreted his actions as a sign of weakness, as he commented that 'a big strong man like you' should not need antidepressants. This type of scenario could compromise Colin's masculine identity, not only through having to ask for help, but also due to the consequences of admitting to taking antidepressants (i.e. peer pressure to be a 'strong man'). 
As previously noted, Connell's (1995) hegemonic masculinity theory has traditionally been used to explain men's approach to care-giving, and within the current study it is a useful framework to interpret data and to explain how the care-giving role can potentially lead to poor care-giving outcomes for older male care-givers (Figure 1). Connell characterises 'normal' masculine behaviour as independent, stoic and self-reliant (Mahalik et al., 2003). Adhering to these ideals can be difficult for men who are navigating family or care-giving situations, and these 'gender norms' can be restrictive for men, particularly in situations where they may need support. Thus, men's need for help and support in their care-giving role can conflict with their masculine identity (O'Neil, 1981). This conflict was described by O’Neil (1981) as gender role conflict. A particular element of gender role conflict is men's tendency to distance themselves from feminine traits or values, sometimes leading to limited choices resulting in poor outcomes for male care-givers, such as increased isolation (Robinson et al., 2014; Greenwood and Smyth, 2015).

This is further illustrated in the current data by the reluctance shown by some study participants to identify themselves as a 'care-giver', or portraying a 'getting on with it' attitude whereby they coped with everything themselves and only sought help when a crisis arose (as these are seen as feminine traits). Reports of intrusion on privacy, dissatisfaction with previous services and a belief that they could cope without additional help resulted in low uptake of support for many participants.

In relation to the question of the influence of gender on care-giving, posed previously, there appears to be a growing recognition of gendered coping strategies (Pretorius et al., 2009; Hong and Coogle, 2014). Calasanti (2006) suggests 'gender different care styles' to explain how men's approach to care-giving is rooted in masculinity, therefore influencing their coping strategies (Hong and Coogle, 2014). However, findings on the impact of gender on care-giving outcomes with other studies are largely inconclusive (Miller and Cafasso, 1992; Pinquart and Sörensen, 2006; Akpinar et al., 2011).

Either way, the emergence of men-centred support programmes targeting physical and mental health, such as 'Man Alive Man Van' (UK) and 'Men's Shed' (Australia and UK/Ireland), are relevant in the debate about gender-based support. These initiatives may reinforce the suggestion that, in terms of support needs, males and females may have different support needs, with males tending to prefer and engage with support which aligns with and does not threaten traditional masculinity ideology.

In the current, and previous studies (Dourado et al., 2010), no data relating to support from external support providers for changing or declining intimacy was found. This could be due to a number of factors, including male care-givers' reluctance to discuss this personal matter or to seek/accept help in their care-giving role, or lack of recognition from health-care support providers about sexuality needs in later life. Recent evidence indicates that health-care practitioners believe that sexuality support is beyond their remit and think that they have inadequate knowledge/ training in this area. There is also evidence to suggest that female health-care staff have less-permissible attitudes in their evaluation of sexual appropriateness than their male counterparts (Haesler et al., 2016). Brotman et al. (2016) go further to point out that the age and gender of health-care professionals affected their comfort levels in this area, and that although staff understood the importance of 
discussing sexuality, they often felt 'awkward' about raising such a personal issue or assumed that it was not a priority for the care-giver. Findings such as these would be particularly important to consider in planning future support for male caregivers. Given the importance of sexual and emotional intimacy for quality of life in ageing and care-giving (Davies et al., 2012; Roelofs et al., 2017), and the reluctance of some male care-givers and health-care practitioners to discuss the issue, there is undoubtedly a need for specialised or gender-specific training in this area for support personnel (Davies et al., 2012).

It is recognised that complex gender dynamics are involved with a female researcher interviewing male participants, and in analysing resulting data. A discussion of this research would not be complete without further consideration of how this was managed and the steps taken to minimise any impact on data. The issue of 'intimacy' had potential to cause discomfort or embarrassment to this cohort of older male care-givers. Even though some previous research has suggested that female researchers may enable male interview participants to 'open up' (Manderson et al., 2007), it is also recognised that a male researcher could have elicited a different response. Arguably, though, so too could a researcher who was a different age or from a different ethnic background. Although the potential for the gendered social context to impact on the data produced could not be totally eliminated, it was managed through regular researcher team meetings, and detailed reflexivity and field notes kept by the researcher who conducted the interviews (AF).

Given the sensitivity of the subject area, maintaining rapport was crucial (Dickson-Swift et al., 2007). Establishment and maintenance of rapport varied, and with the small number of participants where rapport was not evident, the issue of sexual intimacy was not pursued.

Findings from the current study would suggest that the role of care-giver impacts on spousal intimacy for older male care-givers in a committed heterosexual relationship. Similar to other studies, data analysis revealed that participants were experiencing declining sexual intimacy after the onset of their partner's chronic illness (Holdsworth and McCabe, 2018); uncertainty around their future care-giving role due to a sense of burden or physical/emotional stress (Harris et al., 2011); and, for some, consideration of institutional placement (Davies et al., 2010).

This study adds to what is known about intimacy in spousal heterosexual relationships when one partner has a chronic illness and both are older. To our knowledge, no other studies have examined spousal intimacy from an older male care-giver's perspective. Also, little is known about the influence of masculinity on older male care-giver's experience of spousal intimacy, therefore, our findings contribute important new data to this emerging body of research.

\section{Study limitations}

As with all research, it is important to acknowledge study limitations and to consider how they may have impacted on findings. First, during the interviews, owing to the sensitive subject nature, 'intimacy' was introduced gradually by the researcher. Depending on initial reactions to this, some participants received further prompts, and some not. It could be argued that this is a limitation as there was a differentiation in questions and prompts between participants. It is also 
noted that as the researcher was female, this may have affected the dynamic of the interviews. Second, although dementia was the chronic condition experienced by the majority of care recipients in the study $(\mathrm{N}=16)$, other chronic conditions were also included in the study. These were stroke, epilepsy, multiple sclerosis, and Parkinson's disease. Consequently, care recipients had a broad range of illness symptoms, which will have impacted on the care-giver experience. Finally, as the sample was recruited mainly through support agencies, it is assumed that they had all received external support, and this may have set them apart from other caregivers who were not receiving any support at all.

\section{Conclusion}

Study findings suggested that whilst all participants experienced a decline of sexual intimacy, some had placed increased importance on emotional intimacy. Others, however, reported frustration and sadness at the decline of both sexual and emotional intimacy, and consequently questioned how much longer they could continue in their care-giving role. A further group of participants did not discuss the area of sexual/emotional intimacy, which may indicate a reluctance to discuss this deeply personal issue, or that it was no longer an area of concern and that other more practical aspects of care-giving were given higher priority. Given the importance of sexual and emotional intimacy for quality of life in ageing and care-giving (Davies et al., 2012; Roelofs et al., 2017), it is noteworthy that the findings did not reveal any evidence of discussions with external support providers around intimacy. It could be suggested that not only are male care-givers unlikely to ask for support around spousal intimacy, due to their 'independent' approach to care-giving (Hong and Coogle, 2014), but that external support providers are hesitant to offer support in this area (Brotman et al., 2016; Haesler et al., 2016). Finally, findings from the current study indicated that future support for spousal male care-givers should consider a tailored approach which includes recognition of gender as a factor in coping, and acknowledges that support for older male care-givers should align with dominant masculine norms.

\footnotetext{
Acknowledgements. The authors wish to acknowledge the male care-givers who gave up their time to be interviewed for this study.
}

Financial support. This work was supported by the HSC Research \& Development Division, Northern Ireland Public Health Agency, UK. The financial sponsors played no role in the design, execution, analysis and interpretation of data, or writing of the study.

Conflict of interest. The authors declare no conflicts of interest.

Ethical standards. The study was granted ethical approval from OREC (UK), Ulster University Filter Committee, and Northern Health and Social Care Trust (REC reference 17/WM/0019).

\section{References}

Akpınar B, Küçükgüçlï $\mathbf{O}$ and Yener G (2011) Effects of gender on burden among caregivers of Alzheimer's patients. Journal of Nursing Scholarship 43, 248-254.

Baikie E (2002) The impact of dementia on marital relationships. Sexual and Relationship Therapy 17, 289-299.

Baker KL, Robertson N and Connelly D (2010) Men caring for wives or partners with dementia: masculinity, strain and gain. Aging \& Mental Health 14, 319-327. 
Boylstein C and Hayes J (2012) Reconstructing marital closeness while caring for a spouse with Alzheimer's. Journal of Family Issues 33, 584-612.

Braun V and Clarke V (2006) Using thematic analysis in psychology. Qualitative Research in Psychology 3, 77-101.

Brotman S, Drummand J, Silverman M, Sussman T, Orzeck P, Barylek L, Wallack I and Billette V (2016) Talking about sexuality and intimacy with women spousal caregivers: perspectives of service providers. Health \& Social Work 41, 263-269.

Buzan T and Buzan B (1994) The Mind Map Book: How to Use Radiant Thinking to Maximize Your Brain's Untapped Potential. New York, NY: Dutton.

Calasanti T (2006) Gender and old age: lessons from spousal care work. In Calasanti T and Slevin K (eds), Age Matters, Re-aligning Feminist Thinking. New York, NY: Routledge, pp. 269-294.

Carers UK (2015) State of Caring 2015. Available at http://www.carersuk.org/stateofcaring.

Chen Y (2014) Differences in outcomes of caregiver support services for male and female carers. Sage Open 4, July-September, doi:10.1177/2158244014548169.

Clarke JA, Inui TS, Silliman RA, Bokhour BG, Krasnow SH and Robinson RA (2003) Patients perceptions of quality of life after treatment for early prostate cancer. Journal of Clinical Oncology 21, 37773784.

Connell RW (1995) Masculinities. Berkeley, CA: California University Press.

Davies HD, Newkirk LA, Pitts CB, Coughlin A, Sridhar SB, McKenzie Zeiss L and Zeiss AM (2010) The impact of dementia and mild memory impairment (MMI) on intimacy and sexuality on spousal relationships. International Psychogeriatrics 22, 618-628.

Davies H, Sridhar S, Newkirk L, Beaudreau S and O'Hara R (2012) Gender differences in sexual behaviours of $\mathrm{AD}$ patients and their relationship to spousal caregiver well-being. Ageing and Mental Health 16, 89-101.

Dickson-Swift V, James EL, Kippen S and Liamputtong P (2007) Doing sensitive research: what challenges do qualitative researchers face? Qualitative Research 7, 327-353.

Dominguez LJ and Barbagallo M (2016) Ageing and sexuality. European Geriatric Medicine 7, 512-518.

Dourado M, Finamore C, Barroso M, Santos R and Laks J (2010) Sexual satisfaction in dementia. Perspectives of patients and spouses. Sexuality and Disability 28, 195-203.

Droes RM, Boelens-van der Knoop BCC, Bos J, Meihuizen L, Ettema TP, Gerristen GL and Scholzel-Dorenbos CJM (2006) Quality of life in dementia perspective. An explorative study of variations in opinions among people with dementia and their professional caregivers, and the literature. Dementia 5, 534-558.

Evans D and Lee E (2014) Impact of dementia on marriage: a qualitative systematic review. Dementia 13, 330-349.

Fileborn B, Hinchliff S, Lyons A, Heywood W, Minichiello V, Brown G, Malta S, Barrett C and Crameri C (2017) The importance of sex, and the meaning of sex and sexual pleasure for men aged 60 and over. Archives of Sexual Behaviour 46, 2079-2110.

Galinsky AM and Waite LJ (2014) Sexual activity and psychological health as mediators of the relationship between physical health and marital quality. Journals of Gerontology: Psychological Sciences and Social Sciences 69B, 482-492.

Greenwood N and Smyth R (2015) Barriers and facilitators for male carers in accessing formal and informal support. A systematic review. Maturitas 82, 162-169.

Griffiths E (1988) No sex please, we're over 60. Nursing Times 84, 34-35.

Haesler E, Bauer M and Fetherstonhaugh D (2016) Sexuality, sexual health and older people, a systematic review of research on the knowledge and attitudes of health professionals. Nurse Education Today 40, $57-71$.

Harris SM, Adams MS, Zubatsky M and White M (2011) A caregiver perspective of how Alzheimer's disease and related disorders affect couple intimacy. Ageing \& Mental Health 15, 950-960.

Hayes J and Boylstein C (2009) Living and loving with dementia, negotiating spousal and caregiving identity through narrative. Journal of Ageing Studies 23, 48-59.

Heiman J, Long Smith S, Fisher W, Sand M and Rosen R (2011) Sexual satisfaction and relationship happiness in midlife in older couples in five countries. Archives of Sexual Behaviour 40, 741-753.

Holdsworth $\mathbf{K}$ and McCabe $\mathbf{M}$ (2018) The impact of dementia on relationships, intimacy and sexuality in later life couples: an integrative qualitative analysis of existing literature. Clinical Gerontologist 41, 3-19. 
Hong SC and Coogle CL (2014) Spousal caregiving for partners with dementia: a deductive literature review testing Calasanti's gendered view of care work. Journal of Applied Gerontology 35, 759-787.

Hrženjak M (2013) Negotiating masculinity in informal paid care work. International Review of Sociology 23, 346-362.

Kaplan L (2001) A couplehood typology for spouses of institutionalised persons with Alzheimer's disease: perceptions of 'we'-'I'. Family Relations 50, 87-98.

Lincoln YS and Guba EG (1985) Naturalistic Inquiry. Newbury Park, CA: Sage.

Mahalik JR, Locke BD, Ludlow LH, Diemer MA, Scott RP, Gottfried M and Freitas G (2003) Development of the conformity to masculine norms inventory. Psychology of Men and Masculinity 4, 3-25.

Manderson L, Bennett E and Andajani-Sutjahjo S (2007) The social dynamics of the interview: age, class \& gender. Qualitative Health Research 16, 1317-1334.

Merrick K, Camic P and O'Shaughnessy M (2016) Couples constructing their experiences of dementia: a relational perspective. Dementia 15, 34-50.

Miller B and Cafasso L (1992) Gender differences in caregiving: fact or artefact? Gerontologist 32, 498-507.

Milligan C and Morbey H (2016) Care, coping \& identity: older men's experiences of caregiving. Journal of Ageing Studies 38, 105-114.

Molyneaux VJ, Butchard S, Simpson J and Murry C (2011) The co-construction of couple hood in dementia. Dementia 11, 483-502.

Nogueira MML, Brazil D, Sousa MFB, Santos RL and Dourado MCN (2013) Sexual satisfaction in dementia. Revista de Psiquiatria Clinica 40, 77-80.

Nogueira MML, Neto JPS, Sousa MFB, Santos RL, Rosa RDL, Belfort T, Torres B and Dourado MCN (2015) Spouse-caregivers' quality of life in Alzheimer's disease. International Psychogeriatrics 27, 837-845.

Nogueira MML, Neto JPS, Sousa MFB, Santos RL, Rosa RDL, Lacerda IB, Baptista MAT and Dourado MCN (2016) Perception of change in sexual activity in people with Alzheimer's disease: view of people with dementia and their spouse caregivers. International Psychogeriatrics 29, 185-193.

O'Neil JM (1981) Patterns of gender role conflict and strain: sexism and fear of femininity in men's lives. Personnel and Guidance Journal 60, 203-210.

O'Shaughnessy M, Lee K and Lintern T (2010) Changes in the couple relationship in dementia care. Dementia 9, 327-258.

Palacios-Ceña D, Carrasco-Garrido P, Hernández-Barrera V, Alonso-Blanco CP, Jiménez-García R and Fernández-de-las-Peñas C (2012) Sexual behaviors among older adults in Spain: results from a population-based national sexual health survey. Journal of Sexual Medicine 9, 121-129.

Pinquart M and Sörensen S (2006) Gender differences in caregiver stressors, social resources, and health: an updated meta-analysis. Journals of Gerontology: Psychological Sciences and Social Sciences 61B, 33-45.

Pleck JH (1981) The Myth of Masculinity. Cambridge, MA: MIT Press.

Pöysti MM, Laakkonen ML, Strandberg T, Savikko N, Tilvis RS, Eloniemi-Sulkava U and Pitkala KH (2012) Gender differences in dementia spousal caregiving. International Journal of Alzheimer's Disease 2012, 162960.

Pretorius C, Walker S and Malan Heyns P (2009) Sense of coherence amongst male caregivers in dementia. A South African perspective. Dementia 8, 70-94.

Quinn-Patton M (2002) Two decades of developments in qualitative inquiry. A personal experiential perspective. Qualitative Social Work 1, 261-283.

Robinson CA, Bottorff JL, Pesut B, Oliffe JL and Thomlinson J (2014) The male face of caregiving: a scoping review of men caring for a person with dementia. American Journal of Men's Health 8, 409-426.

Roelofs TX, Luijkx KG and Embregts PJ (2017) Love, intimacy, and sexuality in residential dementia care: a spousal perspective. Dementia 18, 936-950.

Rusbult CE (1983) A longitudinal test of the investment model: the development (and deterioration) of satisfaction and commitment in heterosexual involvements. Journal of Personality and Social Psychology 45, 101-117.

Russell R (2007) The work of elderly men caregivers: from public careers to an unseen world. Men and Masculinities 9, 298-314.

Sandberg L (2013) Just feeling a naked body close to you: men, sexuality and intimacy in later life. Sexualities 16, 261-282.

Silverman D (2004) Qualitative Research: Theory, Method and Practice. London: Sage. 
Simonelli C, Tripodi F, Rossi R, Fabrisi A, Lembo D, Cosmi V and Pierleoni L (2008) The influence of caregiver burden on sexual intimacy and marital satisfaction in couples with an Alzheimer's spouse. International Journal of Clinical Practice 62, 47-52.

Sinnott J and Shifren K (2001) Gender and ageing: gender differences and gender roles. In Birren J and Schai K (eds), Handbook of the Psychology of Ageing. San Diego, CA: Academic Press, pp. 454-476.

Sternberg RJ (1997) Construct validation of a triangular love scale. European Journal of Social Psychology 27, 313-335.

Svetlik RND, Dooley WK, Weiner MF, Williamson GM and Walters AS (2005) Declines in satisfaction with physical intimacy predict caregiver perceptions of overall relationship: a study of elderly caregiving spousal dyads. Sexuality and Disability 23, 65-79.

Thorpe R, Hawkes G, Dune T, Fileborn B, Pitts M and Minichiello V (2017) Hidden boundaries and shared meanings: the roles of researcher characteristics and cultural norms in shaping understandings of sexuality in the unstructured interview setting. International Journal of Social Research Methodology 21, 205-217.

Waite IJ, Iveniuk J, Laumann EO and McClintock M (2017) Sexuality in older couples: individual and dyadic characteristics. Archives of Sexual Behaviour 46, 605-618.

Youell J and Callaghan J (2016) 'I don't know if you want to know this': carers' understanding of intimacy in long-term relationships when one partner has dementia. Ageing \& Society 35, 946-967.

Cite this article: Fee A, Mcllfatrick S, Ryan A (2021). 'When it faded in her ... it faded in me': a qualitative study exploring the impact of care-giving on the experience of spousal intimacy for older male care-givers. Ageing \& Society 41, 29-50. https://doi.org/10.1017/S0144686X19000850 